\title{
Implementation of Complex Gas Sensor Systems: Ideas for a Structural Model
}

\author{
Wolfhard Reimringer, Julian Howes, Thorsten Conrad \\ $3 S \mathrm{GmbH}, 66121$ Saarbruecken, Germany \\ reimringer@3S-ing.de
}

\begin{abstract}
Assessing gas mixtures is a task of tremendous complexity, especially when using cost efficient chemical sensors. Current research topics tend to concentrate on materials, processing, data analysis and simulations of promising target applications. However, successful commercialization of gas sensing solutions needs to cover the complete scope of the corresponding problem. Blind spots will cause false interpretation of results, overestimation of performance and inevitably result in overall failure. As a step towards a universal scheme for gas sensing devices and systems, a structural model for these is proposed inspired by the ISO-OSI model for communication networks. It is intended to support development for a specific task as well as laying out the general idea of complex commercial or research projects. Main benefits are instant overview over the technology, indication of completeness and interface definition between sub-systems and project groups. In order to cover general considerations on the meaningfulness of the target application, additional logical layers that go beyond the technological scope are included organically. Examples are given to demonstrate applicability to current implementations of devices and systems. Further work will include refining layer and interface definitions as well as evaluating quantification methods for system performance; application notes shall be developed in collaboration with the sensor community.
\end{abstract}

Key words: Gas sensor, sensor systems, structural model, project planning, interface definition, interdisciplinary collaboration

\section{Introduction}

Developing sensor systems that produce meaningful information on gas atmospheres in the context of a specific application is a complex task. Popular aspects in current research cover sensor material qualification and processing, data analysis techniques and simulations of target scenarios. In a commercial context, ideas from those fields have to be integrated into a solution for the customer's actual needs, while maintaining a thorough understanding for working principles and limitations of the methods put in use. Neglecting this will likely lead to false interpretation of results, overestimation of performance and inevitably cause overall failure as detailed in [1] and [2].

It is important to check a resulting work concept for completeness regarding functional and nonfunctional requirements. One feasible albeit time-consuming approach is to identify use cases from which requirements and specifications can be derived. A comprehensive guide for this strategy is given in [3]. Fig. 1 shows an application specific example for an air quality monitoring network (cf. Fig. 5). Here, all steps in the product life cycle are represented by so-called super use cases which bundle the underlying detailed use cases. From these, many requirements for handling and operation of sensor devices and software components can be derived - though without specifying a sensible structure for actual implementation. This kind of structure is, however, required for the assessment of the interaction between components and sub-systems.

In order to streamline collaboration between experts in the various fields of gas assessment and to facilitate completion of marketable solutions, it seems essential to sketch out all necessary aspects within the toolchain and to highlight the interfaces.

\section{Sensor System Interconnection model (SSI)} Inspired by the ISO-OSI model [4] which covers the interconnection between communication systems, a Sensor System Interconnection model (SSI) is proposed in Fig. 1. The layers are numbered and ordered by descending levels of abstraction. 


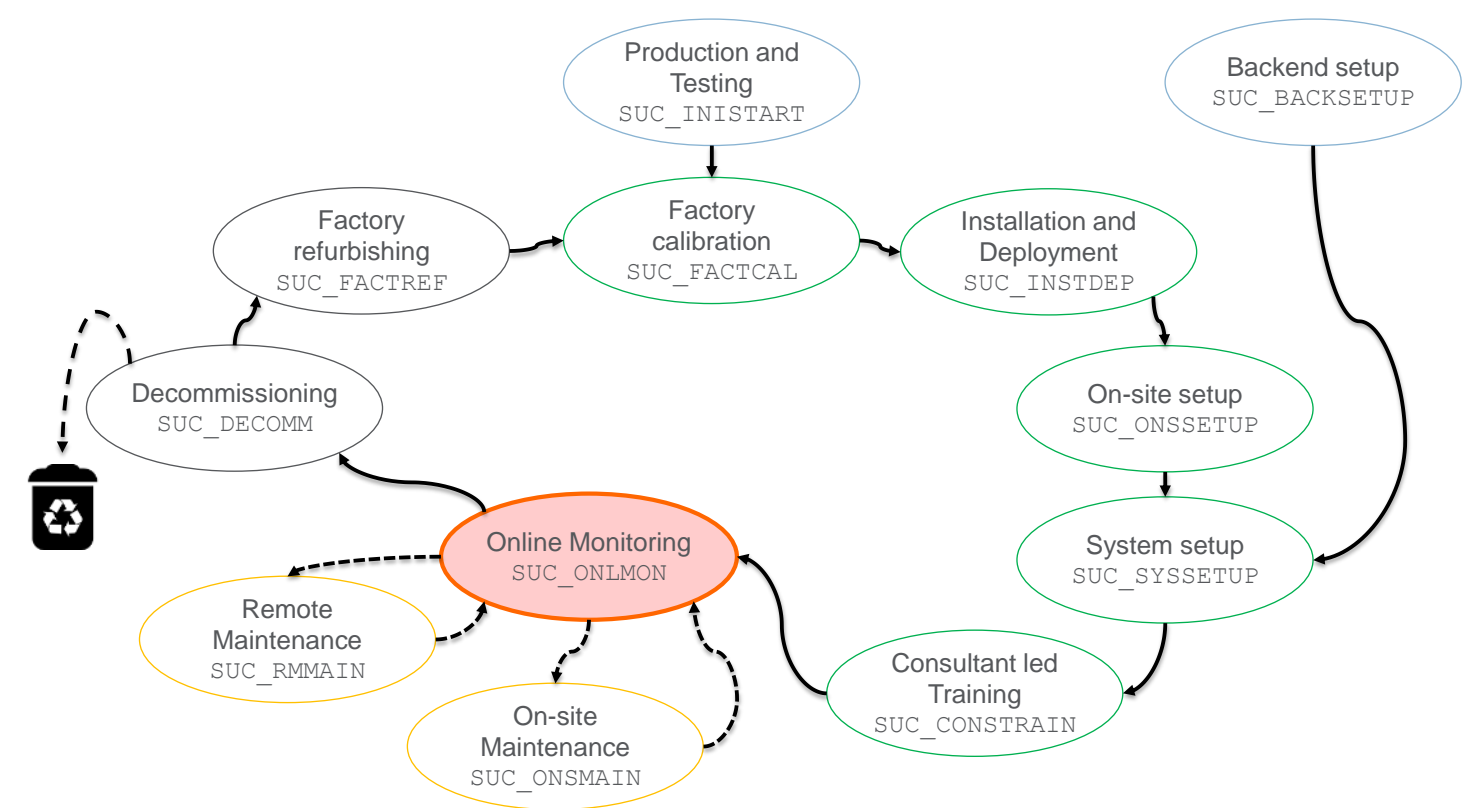

Fig. 1. Super-Use-Cases in a gas sensing device life cycle

\begin{tabular}{|c|c|}
\hline$\# 10$ & Key Benefits \\
\hline$\# 9$ & Application Parameters \\
\hline$\# 8$ & Data Management \\
\hline$\# 7$ & Value Derivation \\
\hline$\# 6$ & Raw Data Acquisition \\
\hline$\# 5$ & Sensor Read-out \\
\hline$\# 4$ & Sensor Operation \\
\hline$\# 3$ & Sensor \\
\hline$\# 2$ & Sampling \\
\hline$\# 1$ & Process/Atmosphere \\
\hline
\end{tabular}

Fig. 2. Layers of the proposed structural model SSI

Layers \#10 and \#9 are best explained topdown, whereas \#1 - \#8 should preferably be considered from the bottom up.

\section{\#10 - Key Benefits}

The question "Why should there be a sensor system?" must raise some valid arguments in order to identify possible funding sources for a project.

\section{\#9 - Application Parameters}

In order to provide the key benefits from \#10, relevant target gases as well as prospective remedies are required to provide a sustainable solution.

\section{\#1 - Process/Atmosphere}

Apart from expected target gases and concentrations, important parameters of the gas matrix in the target application include pressure, temperature as well as interfering and corroding gases. Temporal changes of these parameters need to be considered as well.

\#2 - Sampling

Various sampling techniques can be used to ensure adequate gas transport to the sensor and may help to boost sensitivity or prevent sensor damage. In addition, fluctuations in the composition and concentration of the target atmosphere can be either averaged or sampled selectively.

\section{\#3 - Sensor}

In general, a set of sensors is selected from a multitude of available technologies. Each sensor provides complementary information on $\# 1$ to allow assessment with regard to \#9 and $\# 10$. Availability at required quantities with sufficient quality and reliability is essential when selecting sensors for field test devices and commercial products.

\section{\#4 - Sensor Operation}

For each sensor in \#3, an appropriate operation technique has to be chosen to provide the desired performance. A prominent example is the control and variation of operation temperatures.

\section{\#5 - Sensor Read-out}

Read-out techniques shall provide maximum sensitivity without interfering with the measurement. Compensation methods for enhancement of linearity and sensor lifetime have to be considered. 


\section{\#6 - Raw Data Acquisition}

Electric signals from \#5 have to be sampled with sufficient resolution; in addition to parameters from \#4 and \#5, timings from \#2 have to be considered.

\section{\#7 - Value Derivation}

For trivial applications, raw data from \#6 is converted into a meaningful target value. For more complex applications, data from multiple sensors may need to be combined. If data aggregation from more than one sensor system is necessary, \#7 has to be functionally integrated with \#8.

\section{\#8 - Data Management}

Complexity of the overall solution directly affects complexity of data management structures, ranging from simple measurement records to extensive data center solutions for sensor networks. A reliable link between the output of \#7 and the information needed in \#9 must be provided.

\begin{tabular}{|c|c|}
\hline \#10 & $\begin{array}{c}\text { Quality control for critical product } \\
\text { package, non-destructive } 100 \% \text { testing }\end{array}$ \\
\hline \#9 & $\begin{array}{l}\text { Characteristics: Leakage rate as ethanol } \\
\text { concentration with threshold; Remedy: } \\
\text { Sort out and scrap leaky packages }\end{array}$ \\
\hline \#8 & $\begin{array}{l}\text { Caching raw data, logging test protocols } \\
\text { and results; output to operator + PLC }\end{array}$ \\
\hline \#7 & $\begin{array}{l}\text { Peak detection and rel. amplitude } \\
\text { evaluation }\end{array}$ \\
\hline \#6 & 12bit ADC, $100 \mathrm{~Hz}$ \\
\hline \#5 & $\begin{array}{l}\text { Linear electrometer type, } \\
\text { constant voltage }\end{array}$ \\
\hline \#4 & $\begin{array}{c}\text { Steady state, } \\
\text { temperature controlled }\end{array}$ \\
\hline \#3 & $\begin{array}{c}\text { MOS sensor, } \mathrm{SnO}_{2} \text { layer on ceramic } \\
\text { substrate with } \mathrm{Pt} \text { heater }\end{array}$ \\
\hline \#2 & $\begin{array}{l}\text { Closed fluid circuit: } \\
\text { Pump, valves, test chamber }\end{array}$ \\
\hline \#1 & Clean air, ethanol \\
\hline
\end{tabular}

Fig. 3. Stand-alone device for leak detection.

\section{Application examples}

The following sections contain application examples based on actual implementations to illustrate the benefits of using SSI. For the sake of brevity, layer descriptions are condensed to few keywords.

\section{Application example 1 - Stand-alone laboratory equipment}

As a minimal example (cf. Fig. 3), a leakage detection system used in quality control for packaged products is structured using SSI. Working in a controlled environment and atmospheric background, a single sensor solution is feasible.

\section{Application example 2 - Indoor air quality node}

Additional sensors may increase stability to interferents, specific sensors are needed for inert gases. In this example, a combination of MOS and r.H./T sensors are used for the actual VOC measurement whereas a NDIR sensor provides $\mathrm{CO}_{2}$ reference data. As can be seen from Fig. 4, integrated sensor sub-systems incorporate multiple SSI layers.

\section{Application example 3 - Ambient air monitoring network}

The device for outdoor ambient air monitoring has a similar structure to the previous example, although geared towards different target gases. One important aspect is the altered role of \#7 where no final result is computed. This task is shifted to a data center solution in \#8 that aggregates data from a sensor network. \#7 is left with the task of preparing data for efficient transmission over a wireless interface to \#8.

In the sensor network structure given in Fig. 5, $n$ network nodes are exemplarily supplemented by a weather station. In the context of emission induced pollution, a second set of key benefits is hinting at possible double-use of information when combined with specific process data to allow for early remediation.

\section{Conclusion and outlook}

An important insight from the considerations above can be phrased as "a real-world solution is more than just a sensor". In order to develop and evaluate such solutions in research activities and commercial projects, the sensor system interchange model SSI is proposed as a suitable planning tool. It is intended to complement general product development strategies like use-case analysis and shall help with technical orientation of the overall design.

Further work will have to assess standard strategies to include non-functional requirements and to quantify system performance. Application notes and white papers are intended to be developed in collaboration with the sensor community. 


\begin{tabular}{|c|c|c|c|}
\hline \#10 & \multicolumn{3}{|c|}{$\begin{array}{l}\text { Comfortable and healthy indoor climate } \\
\text { with minimal energy consumption }\end{array}$} \\
\hline$\# 9$ & \multicolumn{3}{|c|}{$\begin{array}{c}\text { Characteristics: Pollutants (benzene, formaldehyde, } \mathrm{TVOC} \text { ), } \mathrm{CO}_{2} \text {, temperature, humidity } \\
\text { Remedies: HVAC, windows, potted plants }\end{array}$} \\
\hline \#8 & \multicolumn{3}{|c|}{$\begin{array}{l}\text { Caching raw data, caching computed data, output to Ul/smartphone, } \\
\text { interface to building automation/data aggregation }\end{array}$} \\
\hline$\# 7$ & \multicolumn{2}{|c|}{$\begin{array}{l}\text { TCO based conversion algorithm with temperature / } \\
\text { humidity compensation }\end{array}$} & \multirow{4}{*}{$\begin{array}{c}\text { Proprietary } \\
\text { with digital interface and } \\
\text { calibrated output }\end{array}$} \\
\hline \#6 & 12bit ADC, $1 \mathrm{kHz}$ & \multirow{3}{*}{$\begin{array}{c}\text { Proprietary } \\
\text { with digital interface }\end{array}$} & \\
\hline$\# 5$ & $\begin{array}{l}\text { Logarithmic } \\
\text { current converter }\end{array}$ & & \\
\hline$\# 4$ & $\begin{array}{l}\text { Temperature control } \\
\text { with cyclic operation }\end{array}$ & & \\
\hline$\# 3$ & $\begin{array}{l}\text { Dual MOS sensor, } \mathrm{SnO}_{2} \\
\mathrm{WO}_{3} \text { on micro hotplates }\end{array}$ & $\begin{array}{l}\text { Integrated capacitive } \\
\text { humidity and temp. sensor }\end{array}$ & Dual beam NDIR \\
\hline \#2 & $\begin{array}{c}\text { Diffusion based via limiting } \\
\text { port }\end{array}$ & $\begin{array}{l}\text { Diffusion based via dust } \\
\text { protected hole }\end{array}$ & $\begin{array}{l}\text { Diffusion based via lateral } \\
\text { opening }\end{array}$ \\
\hline$\# 1$ & \multicolumn{3}{|c|}{$\begin{array}{c}\text { Pollutants from \#9+other VOCs (ethanol, perfumes etc.) }+\mathrm{CO}+\mathrm{H}_{2} \\
\text { humidity, dust }\end{array}$} \\
\hline
\end{tabular}

Fig. 4. Indoor air quality node.

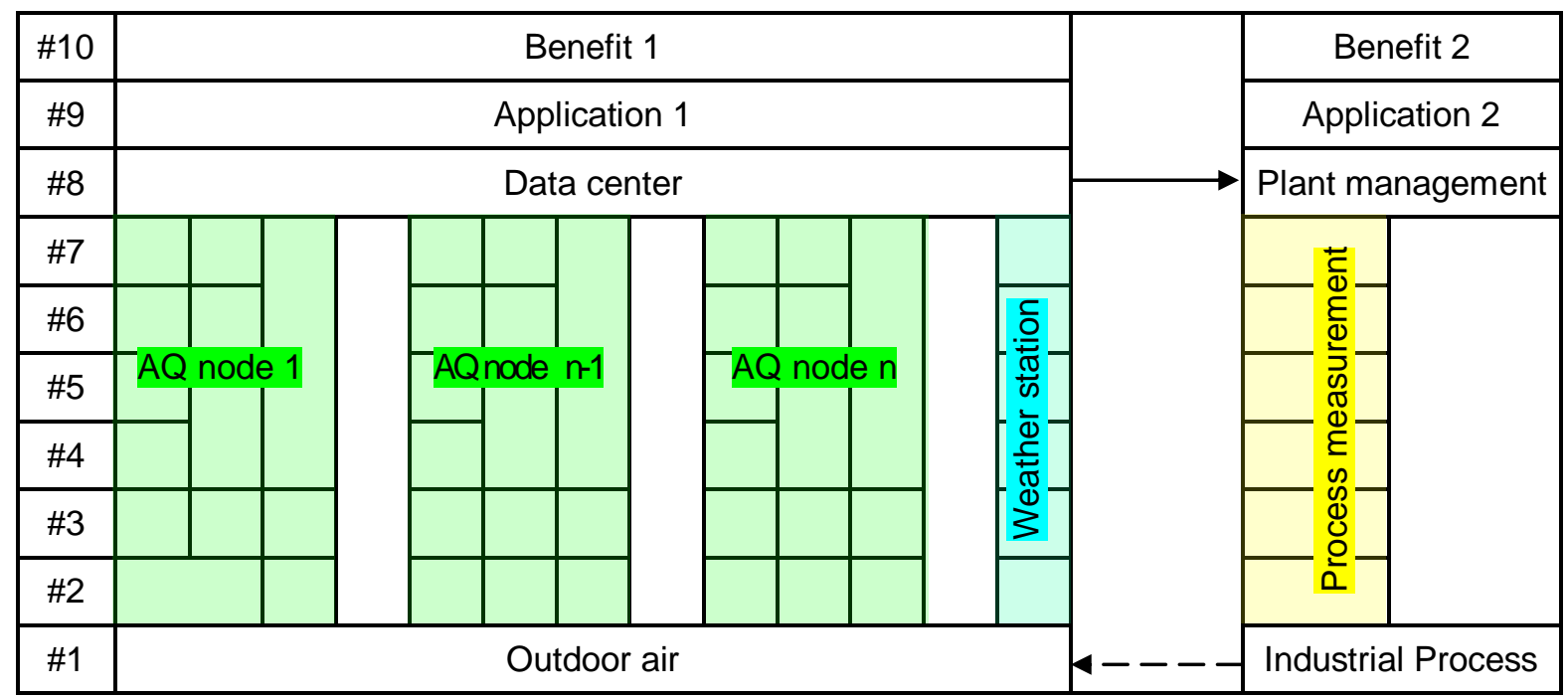

Fig. 5. Ambient air monitoring network

\section{Acknowledgements}

Part of this work was supported by the COST Action TD1105 EuNetAir "European Network on New Sensing Technologies for Air-Pollution Control and Environmental Sustainability".

\section{References}

[1] P. Boeker, On 'Electronic Nose' methodology, Sensors and Actuators B 204 2-17 (2014).

[2] P. Boeker, E-nose: Correlation versus causality The WYSIWYG fallacy, ISOEN Dijon (2015).

[3] A. Cockburn, Writing Effective Use Cases, Addison-Wesley (2000).

[4] ITU-T, Information technology - Open Systems Interconnection - Basic Reference Model: The basic model, ITU-T X.200 (07/1994). 